\title{
Safety risk assessment of cast-in-situ box girder of mountainous high-pier interchange
}

\section{Yong Zeng PhD}

Professor, State Key Laboratory of Mountain Bridge and Tunnel Engineering, Chongqing Jiaotong University, Chongqing, P. R. China; Mountain Bridge and Materials Engineering Research Center of Ministry of Education, Chongqing Jiaotong University, Chongqing, P. R. China

\section{Changchun Yang MEng}

Research Assistant, State Key Laboratory of Mountain Bridge and Tunne Engineering, Chongqing Jiaotong University, Chongqing, P. R. China; Mountain Bridge and Materials Engineering Research Center of Ministry of Education, Chongqing Jiaotong University, Chongqing, P. R. China

\section{Qianping Zhang MEng}

Research Assistant, State Key Laboratory of Mountain Bridge and Tunnel Engineering, Chongqing Jiaotong University, Chongqing, P. R. China; Mountain Bridge and Materials Engineering Research Center of Ministry of Education, Chongqing Jiaotong University, Chongqing, P. R. China

\section{Hongmei Tan PhD}

Associate Professor, State Key Laboratory of Mountain Bridge and Tunnel Engineering, Chongqing Jiaotong University, Chongqing, P. R. China; Mountain Bridge and Materials Engineering Research Center of Ministry of Education, Chongqing Jiaotong University, Chongqing, P. R. China (Orcid:0000-0002-6288-4089) (corresponding author:

hmtan@cqjtu.edu.cn, hmtan2009@126.com)

The safety risk events that may occur during the cast-in-situ process of a concrete box girder of an interchange bridge with high piers in mountainous areas are briefly listed. Based on the background of an interchange project in Yunnan province, China, the relative importance weights of selected safety risk events are calculated by an analytic hierarchy process, and the uncertainty and fuzziness of the analytic hierarchy process are solved using the cloud theory to improve the accuracy of the analytic hierarchy process; then the improved likelihood-exposure-criticality method is used to evaluate the risk level of safety risk events. It is verified that the use of back-propagation-neural network theory can realize the risk prediction of engineering projects based on human factors and environmental factors. At the same time, real-time risk prediction based on dimension and space dimension is necessary, and it also provides a new idea for security risk assessment.

\section{Notation}

$a_{i j} \quad$ ratio of importance of matrix elements

$B_{i} \quad$ target elements

$D \quad$ hazard and the risk grade of the construction operation

$E \quad$ social impact caused by the accident

$E_{n} \quad$ entropy

$E_{x} \quad$ expectation

$H_{e} \quad$ hyper-entropy

$K \quad$ possibility of safety accident

$L \quad$ relative importance weight of each risk calculated by the analytic hierarchy process

$M \quad$ direct economic loss caused by accident

$n \quad$ matrix order

$P \quad$ casualties caused by the accident

$T \quad$ time loss caused by the accident

$\boldsymbol{W}_{\mathrm{A}} \quad$ weight vector from formula in table

$W_{i, j} \quad$ connection weight between the input layer and the hidden layer

$W_{j, i} \quad$ connection weight between the hidden layer and the output layer

$\lambda_{\max } \quad$ maximum characteristic root

$\mu_{i} \quad$ degree of certainty

\section{Introduction}

According to the existing data, there have been safety accidents in the past related to the bridge construction process.
Minor safety accidents do not affect the progress of construction, do not cause casualties and do not cause economic losses, while major safety accidents produce heavy casualties and economic losses, as well as adverse social impact. The construction process of high-pier bridges in mountainous areas faces more complicated construction environments, more stringent construction techniques and more potential safety hazards than in inland regions ( $\mathrm{Lu}$ et al., 2014). In order to avoid the occurrence of safety accidents during the construction of high-pier bridges in mountainous areas, it is necessary to carry out a safety risk assessment. An analysis of 47 safety incidents relating to bridge construction found that 13 bracket failure incidents occurred, accounting for 27.6\%; seven accidents involving a fall from high altitude occurred, accounting for $14.9 \%$; and nine mechanical injury accidents occurred, accounting for $19.1 \%$; there were 13 accidents involving bridge collapse (most of which occurred during the construction of arch bridges, and fewer beam bridges), accounting for $27.6 \%$; four accidents of mouldboard destruction occurred, accounting for $8.5 \%$; and one other safety accident occurred, accounting for $2.1 \%$. From these data, it is known that the higher accident occurrence rates during the bridge construction stage are bracket failure safety accidents and bridge collapse safety accidents, followed by mechanical injury accidents, high-altitude fall accidents, mouldboard destruction accidents and then other safety accidents. 


\begin{tabular}{|c|c|c|c|}
\hline A-B judgement matrix & $\begin{array}{l}\text { Product of elements } \\
\text { in each row }\end{array}$ & $\begin{array}{l}N \text { th root of the product of } \\
\text { elements in each row }\end{array}$ & Normalisation \\
\hline $\begin{array}{llll}A & B_{1} & B_{2} & B_{3}\end{array}$ & $M_{i}=\prod_{j=1}^{n} a_{i j}$ & $m_{i}=\sqrt[n]{M_{i}}$ & $W_{i}=m_{i} / \sum_{j=1}^{n} m_{i}$ \\
\hline $\begin{array}{llll}B_{1} & a_{11} & a_{12} & a_{13}\end{array}$ & $M_{1}$ & $m_{1}$ & $w_{1}$ \\
\hline $\begin{array}{llll}B_{2} & a_{21} & a_{22} & a_{23}\end{array}$ & $M_{2}$ & $m_{2}$ & $w_{2}$ \\
\hline $\begin{array}{llll}B_{3} & a_{31} & a_{32} & a_{33}\end{array}$ & $M_{3}$ & $m_{3}$ & $w_{3}$ \\
\hline
\end{tabular}

How to quickly, efficiently and accurately carry out safety risk assessments is the focus of the current paper. Two different assessment systems are adopted for the safety risk assessment of cast-in-situ concrete box girders of interchange with high piers in mountainous areas. Method 1 combines multiple methods of evaluation to improve the accuracy of the assessment results, and is applied to engineering examples. Method 2 proposes a time-sensitive security risk assessment method for real-time observation of project risks.

\section{Safety risk assessment method}

There are many methods of security risk assessment, the most common are sensitivity analysis, the analytic hierarchy process (AHP), expert scoring method, fuzzy comprehensive evaluation method, Monte Carlo method and fault tree analysis (Deng et al., 2012; He et al., 2016; Liu et al., 2017; Nariman, 2017; Tong and Yang, 2017; Yazdi et al., 2017). Each of these security risk assessment methods has its own unique advantages and disadvantages, and they can be combined to make the various methods complementary to each other, giving full scope to the advantages of each, and thereby improving the accuracy and effectiveness of safety risk assessment. The AHP, cloud theory, improved likelihood-exposure-criticality (LEC) method and back-propagation (BP)-neural network method will all be briefly introduced in this section, and a theoretical preparation will be made for combining these methods to make a safety risk assessment of a cast-in-situ concrete box girder of interchange with high piers in mountainous areas.

\subsection{Analytic hierarchy process}

In the early 1970s, American operations researcher, Saaty, proposed the AHP. This method breaks down the elements related to the research item into the levels of goals, criteria and schemes by establishing a structural hierarchy model, followed by qualitative and quantitative analysis (Raka and Liangrokapart, 2017; Zayed et al., 2007). In the process of organising the goals at each level, the target elements $\left(B_{i}\right)$ in each level should not be too numerous, as an excessive number of elements will make the comparison between the elements complicated. Therefore, the risk hierarchy judgement matrix generally does not exceed the ninth order. The specific calculation process is shown in Table 1 .
$\boldsymbol{W}_{\mathrm{A}}=\left(w_{1}, w_{2}, w_{3}\right)^{\mathrm{T}}$, where $\boldsymbol{W}_{\mathrm{A}}$ is the weight vector from the formula in Table $1 ; a_{i j}$ is the ratio of importance of the matrix elements. The assignment of $a_{i j}$ will directly affect the final calculation result, and its assignment is shown in Table 2. If the ratio of importance of element $i$ to element $j$ is $a_{i j}$, then the ratio of importance of element $j$ to element $i$ is $1 / a_{i j}$.

The consistency check can be expressed as

1a. $\lambda_{\max }=\sum_{i}^{n} \frac{\left(A \cdot \boldsymbol{W}_{A}\right)_{i}}{n v \boldsymbol{W}_{A i}}$

1b. $\mathrm{CR}=\frac{\lambda_{\max }-n}{\mathrm{RI}(n-1)}$

where $\lambda_{\max }$ is the maximum characteristic root; $n$ is the matrix order; CR is the decision value of consistency check; RI is the consistency index value. The value of RI is related to the matrix order $n$. As the order increases, the value of RI becomes larger, as shown in Table 3.

Table 2. Denotation of matrix element $\left(a_{i j}\right)$ assignment

\begin{tabular}{ll} 
Denotation & Assignment \\
\hline $\begin{array}{l}\text { Two elements are equally important } \\
\text { The former is slightly more important than the }\end{array}$ & 1 \\
$\quad$ latter & 3 \\
The former is more important than the latter & 5 \\
The former is significantly more important than the & 7 \\
$\quad$ latter & \\
The former is extremely more important than the & 9 \\
$\quad$ latter & $2,4,6,8$ \\
$\begin{array}{l}\text { Intermediate value of the above adjacent } \\
\text { judgements }\end{array}$
\end{tabular}

Table 3. Assignment of RI

\begin{tabular}{llllrl}
$\boldsymbol{n}$ & $\mathbf{R I}$ & $\boldsymbol{n}$ & $\mathbf{R I}$ & $\boldsymbol{n}$ & $\mathbf{R}$ \\
\hline 1 & 0 & 5 & 1.12 & 9 & 1.46 \\
2 & 0 & 6 & 1.24 & 10 & 1.49 \\
3 & 0.52 & 7 & 1.36 & 11 & 1.51 \\
4 & 0.89 & 8 & 1.41 & 12 & 1.54 \\
\hline
\end{tabular}


When CR is less than 0.1 , the judgement matrix conforms to the consistency test, and the calculation results can be used directly. If CR is not less than 0.1 , the matrix elements should be reassigned.

\subsection{Cloud theory model}

In order to solve the defects of probability theory and fuzzy mathematical theory in the process of dealing with uncertainty problems, Professor Li Deyi proposed the concept of a cloud model ( $\mathrm{Li}$ and Meng, 1995). The basis of cloud model theory is actually the mutual conversion between qualitative concepts and values with fuzziness and randomness, and the qualitative evaluation of natural language from the mathematical point of view. The commonly used digital features are expectation $\left(E_{x}\right)$, entropy $\left(E_{n}\right)$, and hyper-entropy $\left(H_{e}\right)$. The cloud generator is divided into two types: forward cloud generator and backward cloud generator. The forward cloud generator is from qualitative concept to quantitative representation and the reverse cloud generator is from quantitative value to qualitative concept (Li et al., 2009; Liu and Zhang, 2018).

\subsubsection{Forward cloud generator algorithm}

The digital features $E_{x}, E_{n}, H_{e}$, representing the qualitative concept of indicator importance and the number of cloud drops $N$ generated, are input. Each cloud drop $x_{i}$ and the corresponding membership are output. The specific algorithm steps are as follows.

(a) Generate a normal random number $x_{i}$ with $E_{n}$ as the expectation and $H_{e}$ as the variance.

(b) Generate a normal random number $x_{i}$ with $E_{x}$ as the expectation and $E_{n}$ as the variance.

(c) Calculate the degree of membership (the degree of certainty), $\mu_{i}=\exp \left[-\left(x_{i}-E_{x}\right)^{2} / 2\left(E_{n}\right)^{2}\right]$.

(d) Repeat the above steps until sufficient cloud droplets are generated.

Table 4. Values for each letter

\begin{tabular}{|c|c|c|c|c|c|c|c|}
\hline & Point value & 10 & 8 & 6 & 3 & & 1 \\
\hline$P$ & Casualties & $\begin{array}{l}\text { Deaths } \geq 30 \text { or } \\
\text { serious } \\
\text { injuries } \geq 100\end{array}$ & $\begin{array}{c}10 \leq \text { deaths }<30 \text { or } \\
50 \leq \text { serious } \\
\text { injuries }<100\end{array}$ & $\begin{array}{c}3 \leq \text { deaths }<10 \\
\text { or } 10 \leq \text { serious } \\
\text { injuries }<50\end{array}$ & $\begin{array}{c}1 \leq \text { deaths }<3 \\
\text { or } 3 \leq \text { serious } \\
\text { injuries }<10\end{array}$ & & $\begin{array}{l}\text { No deaths } \\
\text { or minor } \\
\text { injuries }\end{array}$ \\
\hline M & $\begin{array}{l}\text { Economic loss: } \\
1160 \text { GBP }\end{array}$ & $>1000$ & $1000 \leq$ loss $<500$ & $500 \leq$ loss $<100$ & $100 \leq$ loss $<50$ & & $<50$ \\
\hline$T$ & $\begin{array}{l}\text { Loss of time: } \\
\text { days }\end{array}$ & $>60$ & $30 \leq$ loss $<60$ & $10 \leq$ loss $<30$ & $2 \leq$ loss $<10$ & & $<2$ \\
\hline$E$ & $\begin{array}{r}\text { Extent of } \\
\text { impact }\end{array}$ & $\begin{array}{l}\text { Above the provincia } \\
\text { level }\end{array}$ & Provincial level & Municipal level & District level & & Partial level \\
\hline & \multicolumn{2}{|c|}{ Point value } & & $0.096-4.2$ & $0.042-0.096$ & \multicolumn{2}{|l|}{0.042} \\
\hline$D$ & \multicolumn{2}{|c|}{$\begin{array}{l}\text { Risk rating } \\
\text { Countermeasure }\end{array}$} & $\begin{array}{l}\text { emely high } \\
\text { icceptable }\end{array}$ & $\begin{array}{l}\text { High } \\
\text { Strict control }\end{array}$ & $\begin{array}{l}\text { Moderate } \\
\text { Rational control }\end{array}$ & \multicolumn{2}{|c|}{$\begin{array}{l}\text { Low } \\
\text { Acceptable }\end{array}$} \\
\hline
\end{tabular}

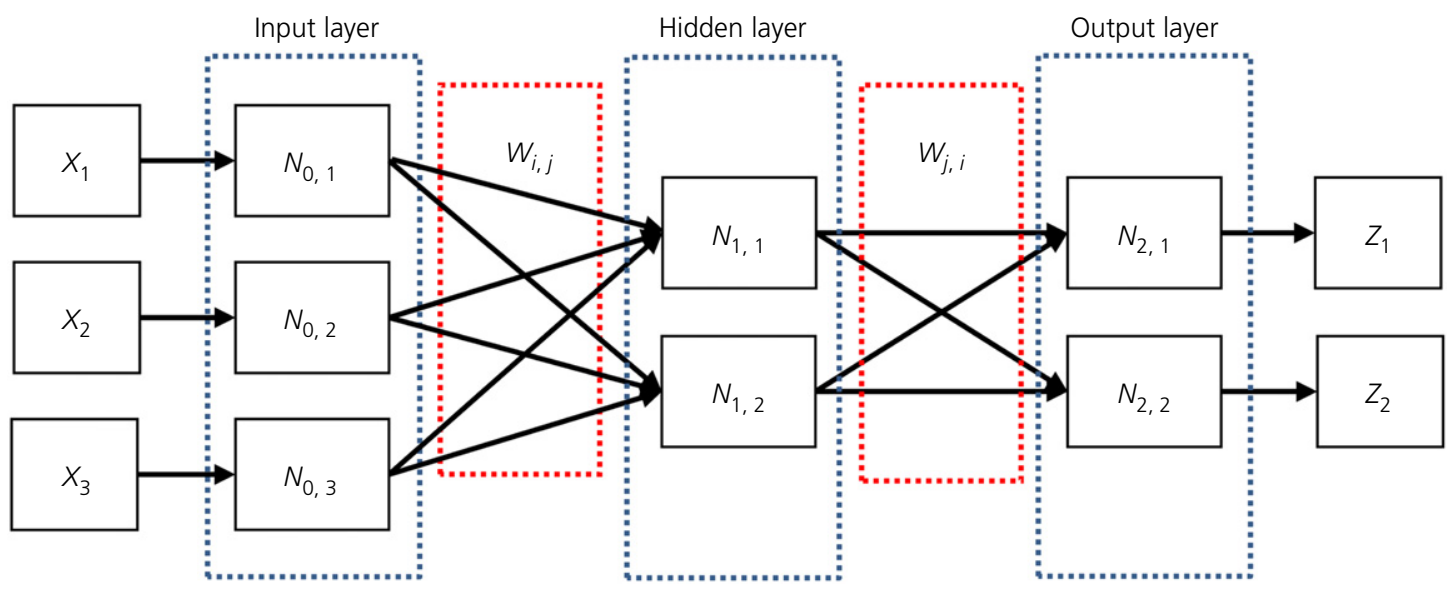

Figure 1. Flowchart of BP neural network 


\subsubsection{Backward cloud generator algorithm}

Backward cloud generator refers to finding $E_{x}, E_{n}, H_{e}$ from given cloud drops. Quantitative values of $N$ cloud drops and the degree of certainty $\left(x_{i}, y_{i}\right)$ of each cloud drop concept are input. Digital features $E_{x}, E_{n}, H_{e}$ represented by $N$ cloud drops are output. The specific algorithm steps are as follows. (a) The sample mean $\bar{x}$ and the sample variance $\left(S^{2}=[1 /(N-1)] \sum_{i=1}^{N}\left(x_{i}-\bar{x}\right)^{2}\right)$ of $N$ cloud drops are calculated from $x_{i}$.

(b) The expectation $E_{x}=\bar{x}$ is found.

(c) The entropy $E_{n}=\sqrt{\pi / 2} \times 1 / N \sum_{i=1}^{N}\left|x_{i}-\bar{x}\right|$ is calculated. (d) The hyper-entropy $H_{e}=\sqrt{S^{2}-E_{n}^{2}}$ is calculated.

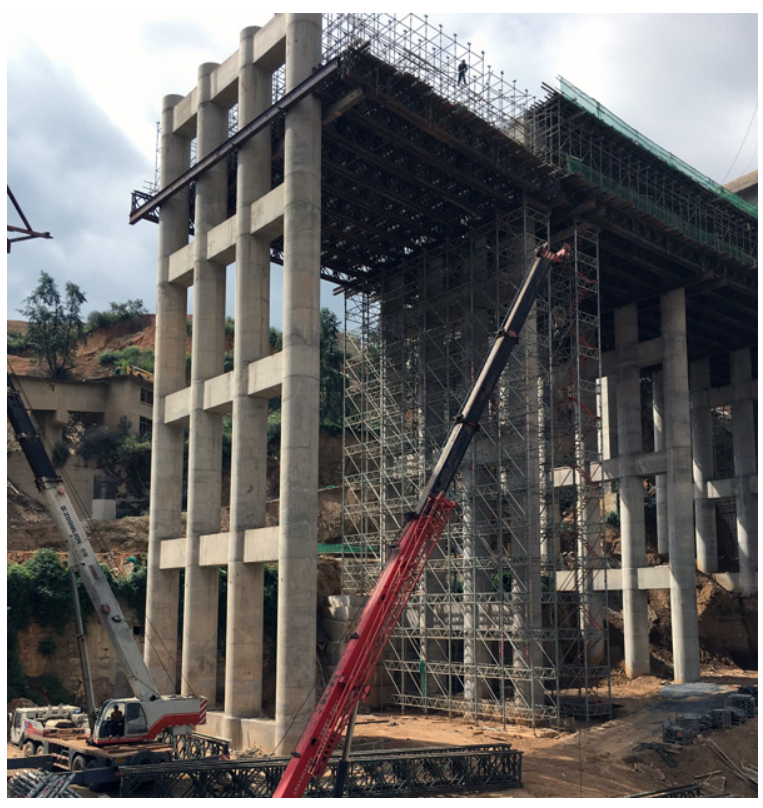

(a)

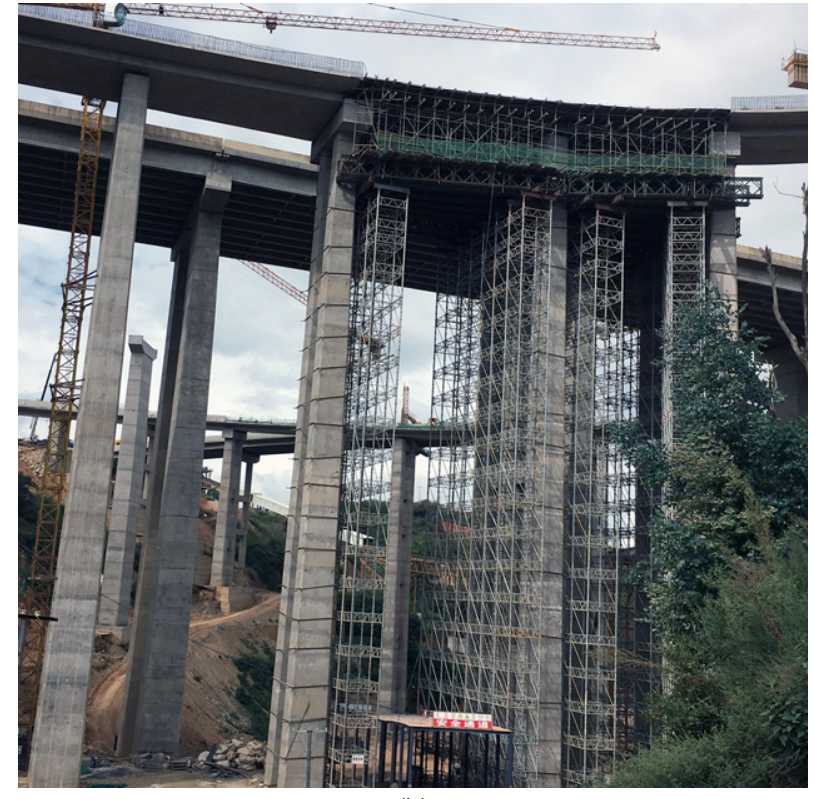

(b)

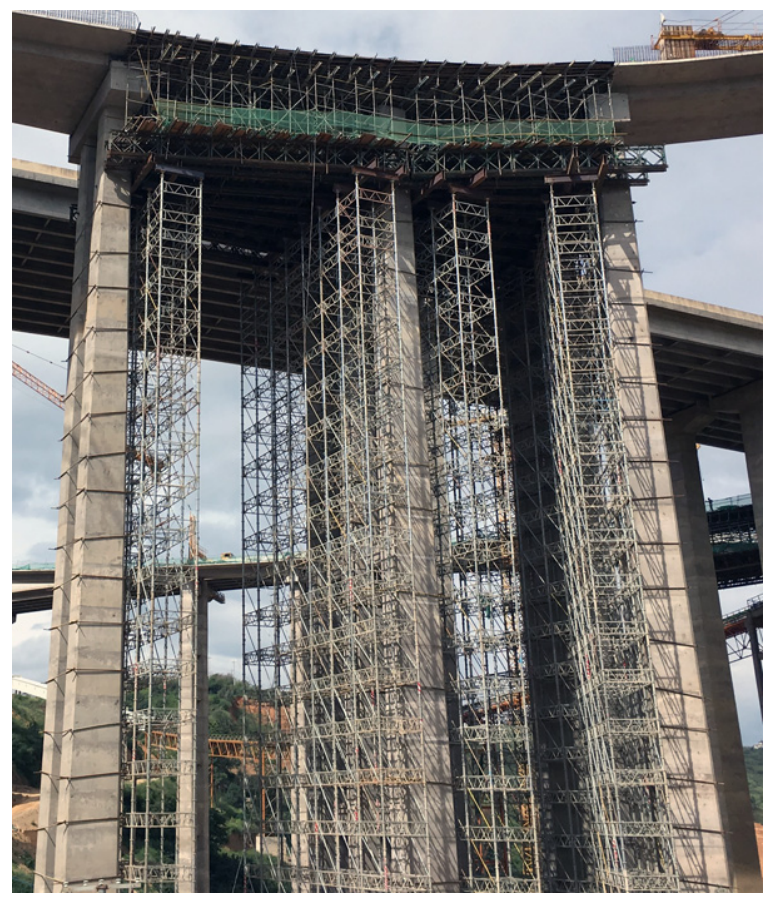

(c)

Figure 2. Some photographs of the construction 


\subsection{Improved LEC method}

The traditional LEC method is mainly used to judge the casualties, because the single evaluation standard cannot accurately and objectively reflect the actual situation of the project safety risk source (Liu and Sun, 2015; Tang et al., 2015). So the improved model is as follows:

$$
D=L \times(P+M+T+E) \times K
$$

where $D$ is the hazard and the risk grade of the construction operation; $L$ is the relative importance weight of each risk calculated by the AHP; $P$ is the casualties caused by the accident; $M$ is the direct economic loss caused by the accident; $T$ is the loss of time caused by the accident; $E$ is the social impact caused by the accident; $K$ is the possibility of the safety accident. The specific values are shown in Table 4.

\subsection{BP neural network theory}

The neural network mainly contains the input layer, the hidden layer and the output layer. The number of neurons in these three layers, however, is not exactly the same, and must be determined according to actual conditions (Chen, 2016; Yin et al., 2011). As shown in Figure 1, where $W_{i, j}$ is the connection weight between the input layer and the hidden layer; $W_{j, i}$ is the connection weight between the hidden layer and the output layer.

The learning process of BP-neural network (Fan, 2011; Ji and Cai, 2016) is divided into two stages - namely, the forward propagation of input information and the backward propagation of error information. When the output result does not match the actual result, the error is back-propagated; the weight of the network is adjusted by error feedback and the actual output of the network is closer to the expected output through the continuous correction of the weight. The errorforward propagation and the error-backward propagation are repeated until the error is zero or convergence occurs.

In this paper, the relative importance weights of the security risk events are calculated by the AHP, and the uncertainty and fuzziness of the AHP are solved using the cloud theory to improve the accuracy of the AHP; then the improved LEC method is used to evaluate the risk level of safety risk events. At the same time, BP-neural network theory is used to analyse the risk prediction and evaluation system based on human factors and environmental factors to verify its feasibility and effectiveness.

\subsection{Application to an engineering example}

An interchange project forms the background of this paper, and a safety risk assessment of the in situ casting process of its high-pier interchange box girder is conducted. The interchange project has a total of 31 links (eight links on the main line and 23 links on the ramp bridge), and 101 spans are cast in situ at the construction site; the sections of all of the bridge are ordinary concrete cast-in-place box girders, and some of the piers are $60 \mathrm{~m}$ high. Some photographs of the construction are shown in Figure 2.

During the cast-in-situ construction process of a high-pier interchange concrete box girder in a mountainous area, safety accidents with a high incidence include bracket safety accidents, falls from high altitude, construction equipment accidents, bridge collapse accidents, as well as other safety-related accidents. The list of possible safety accidents for the cast-in-situ process selected in this paper is shown in Figure 3.

\subsection{Risk estimation}

In this section the AHP is mainly used to obtain the relative importance weight value of safety accidents that may occur during the cast-in-situ construction process. First, the nine elements B1-B9 in the criterion layer of Figure 3 are passed to six people with relevant experience to judge the relative importance of two adjacent risk events, and each expert's judgement matrix regarding the relative importance of each risk event is obtained. Then the relative importance weight value of each risk event according to each expert's judgement is calculated using the AHP. Finally, the consistency of evaluation of the various risk events by the experts is verified by way of the cloud theory model, and the relative importance weight value will thereby be obtained for the nine types of safety risk events that may occur in the cast-in-situ

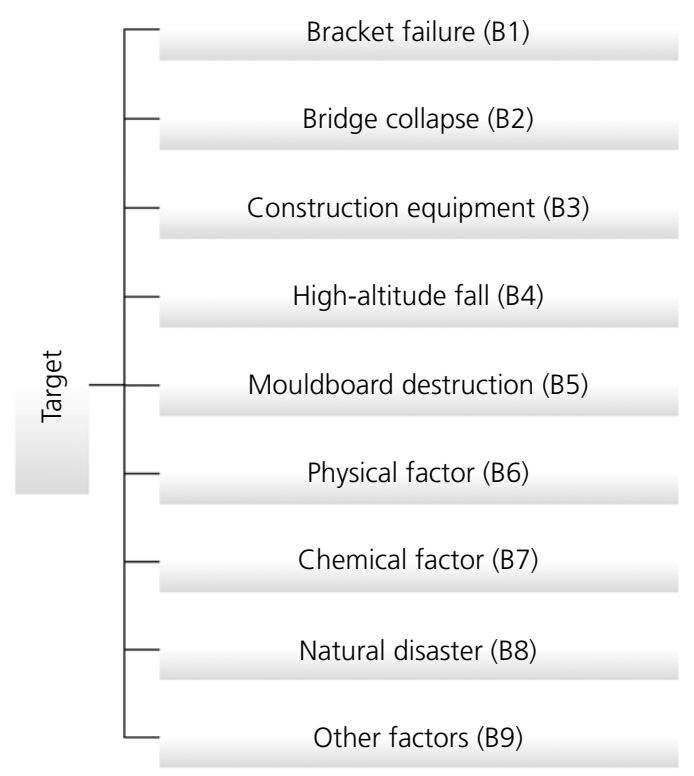

Figure 3. Target-based safety accident selection results 
Table 5. Judgement matrix of expert number 1 on the relative importance of each risk event

\begin{tabular}{|llllllllll} 
Expert no. 1 & B1 & B2 & B3 & B4 & B5 & B6 & B7 & B8 & B9 \\
\hline B1 & 1 & 4 & 3 & 4 & 4 & 3 & 3 & 7 & 4 \\
B2 & $1 / 4$ & 1 & $1 / 3$ & $1 / 3$ & $1 / 2$ & $1 / 4$ & 2 & 3 & $1 / 3$ \\
B3 & $1 / 3$ & 3 & 1 & 2 & 3 & 3 & 3 & 5 & 2 \\
B4 & $1 / 4$ & 3 & $1 / 2$ & 1 & 3 & 3 & 2 & 5 & 2 \\
B5 & $1 / 4$ & 2 & $1 / 3$ & $1 / 3$ & 1 & $1 / 2$ & 2 & 3 & 2 \\
B6 & $1 / 3$ & 4 & $1 / 3$ & $1 / 3$ & 2 & 1 & 2 & 3 & 2 \\
B7 & $1 / 3$ & $1 / 2$ & $1 / 3$ & $1 / 2$ & $1 / 2$ & $1 / 2$ & 1 & 3 & 2 \\
B8 & $1 / 7$ & $1 / 3$ & $1 / 5$ & $1 / 5$ & $1 / 3$ & $1 / 3$ & $1 / 3$ & 1 & $1 / 3$ \\
B9 & $1 / 4$ & 3 & $1 / 2$ & $1 / 2$ & $1 / 2$ & $1 / 2$ & $1 / 2$ & 3 & 1
\end{tabular}

Table 6. Relative importance weight values of the six experts for each risk event

\begin{tabular}{|lcccccccccc} 
No. of experts & B1 & B2 & B3 & B4 & B5 & B6 & B7 & B8 & B9 \\
\hline 1 & 0.294 & 0.051 & 0.178 & 0.141 & 0.078 & 0.102 & 0.062 & 0.027 & 0.066 \\
2 & 0.278 & 0.045 & 0.135 & 0.145 & 0.124 & 0.110 & 0.056 & 0.024 & 0.083 \\
3 & 0.249 & 0.042 & 0.178 & 0.166 & 0.103 & 0.091 & 0.056 & 0.025 & 0.090 \\
4 & 0.281 & 0.056 & 0.127 & 0.143 & 0.135 & 0.084 & 0.055 & 0.026 & 0.094 \\
5 & 0.240 & 0.040 & 0.135 & 0.186 & 0.092 & 0.109 & 0.058 & 0.023 & 0.118 \\
6 & 0.270 & 0.048 & 0.146 & 0.155 & 0.109 & 0.084 & 0.057 & 0.025 & 0.106
\end{tabular}

process of a high-pier interchange concrete box girder in this mountainous area.

Taking the assessment of expert number 1 as an example, the judgment matrix on the relative importance of each risk event is shown in Table 5.

Calculation by the aforementioned theoretical formulas gives

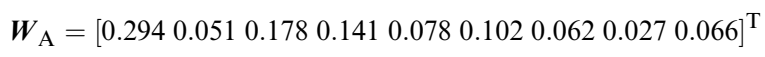

is verified by using the cloud theory model. The initial inspection cloud diagram is shown later in Figure 5, where the abscissa is the relative importance weight value of $\mathrm{B} 8$ and the ordinate is the degree of certainty $\left(\mu_{i}\right)$. As can be seen from Figure 4, in the probability cloud diagram of this risk event $\mathrm{B} 8$, the cloud droplets are less discrete, so it can be concluded that the evaluation of the relative importance of this risk event by six experts meets the consistency requirements.

The cloud theory model finally obtains the relative importance weight values, $W=E_{x}=\left[\begin{array}{llllll}0.269 & 0.047 & 0.150 & 0.156 & 0.107 & 0.097\end{array}\right.$

$$
\lambda_{\max }=\sum_{i}^{n} \frac{A \cdot \boldsymbol{W}_{A i}}{n \cdot \boldsymbol{W}_{A i}}=\frac{1}{9}\left(\frac{2.858}{0.294}+\frac{0.523}{0.051}+\frac{1.707}{0.178}+\frac{1.390}{0.141}+\frac{0.749}{0.078}+\frac{1.005}{0.102}+\frac{0.619}{0.062}+\frac{0.253}{0.027}+\frac{0.655}{0.066}\right)=9.779
$$

$$
\mathrm{CR}=\frac{\lambda_{\max }-n}{(n-1) \times \mathrm{RI}}=\frac{9.779-9}{8 \times 1.46}=0.067<0.100
$$

Therefore, the judgement matrix of the expert number 1 meets the requirements of consistency. So, matrix $\boldsymbol{W}_{\mathrm{A}}$ can be used as the relative importance weight value of each risk event.

Similarly, the relative importance weight values of the remaining experts to each risk event can be calculated, as shown in Table 6 .

The risk event B8 is taken as an example in this paper, and the consistency of multiple experts' judgements on this risk event

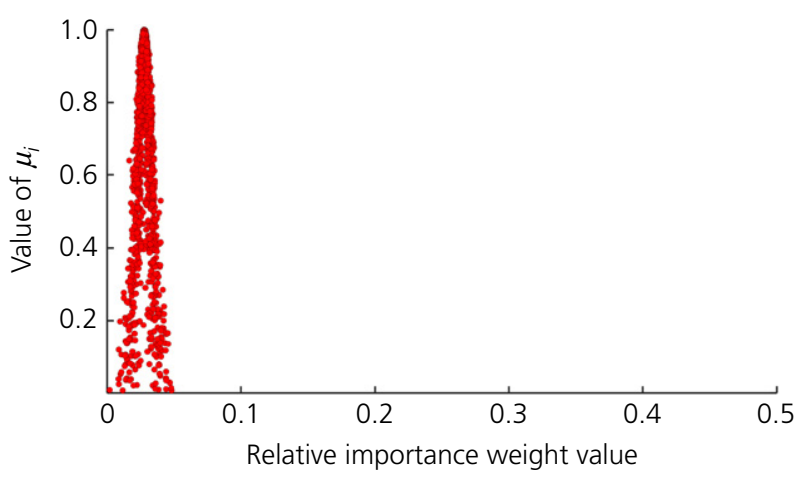

Figure 4. Probabilistic cloud diagram of the eighth risk event 
Table 7. Level assessment of each risk event by six experts

\begin{tabular}{lcccccc} 
& Expert no. 1 & Expert no. 2 & Expert no. 3 & Expert no. 4 & Expert no. 5 & Expert no. $\mathbf{~}$ \\
\hline D1 & 0.207 & 0.235 & 0.211 & 0.198 & 0.169 & 0.190 \\
D2 & 0.062 & 0.044 & 0.041 & 0.068 & 0.034 & 0.041 \\
D3 & 0.050 & 0.038 & 0.067 & 0.048 & 0.038 & 0.069 \\
D4 & 0.066 & 0.068 & 0.062 & 0.067 & 0.077 & 0.044 \\
D5 & 0.055 & 0.087 & 0.087 & 0.095 & 0.052 & 0.077 \\
D6 & 0.029 & 0.034 & 0.038 & 0.039 & 0.032 & 0.039 \\
D7 & 0.061 & 0.039 & 0.039 & 0.047 & 0.041 & 0.040 \\
D8 & 0.033 & 0.029 & 0.028 & 0.032 & 0.019 & 0.025 \\
D9 & 0.025 & 0.039 & 0.038 & 0.027 & 0.052 & 0.040
\end{tabular}

$0.0570 .0250 .092]$, which may occur during the cast-in-situ process of a high-pier interchange concrete box girder in the mountainous area. The order of numerical values are: bracket failure (B1), high-altitude fall (B4), construction equipment (B3), mouldboard destruction (B5), physical factor (B6), other factors (B9), chemical factor (B7), bridge collapse (B2) and natural disaster (B8).

\subsection{Risk assessment}

The improved LEC method is used to evaluate each security risk event, and the resulting risk level assessment is shown in Table 7.

To verify the consistency of the six experts' assessments of each risk event, the cloud theory model is also used for consistency checking, and the first risk event (B1) is taken as an example. The initial inspection cloud diagram is shown in Figure 5, where the abscissa is the point value of risk level of $\mathrm{B} 1(D)$ and the ordinate is the degree of certainty $\left(\mu_{i}\right)$. At the same time, it can be seen that the degree of separation of cloud droplets is large, which indicates that the opinions of the experts are inconsistent.

Therefore, this risk event must be re-assigned and evaluated. The second consistency check cloud after reassignment and

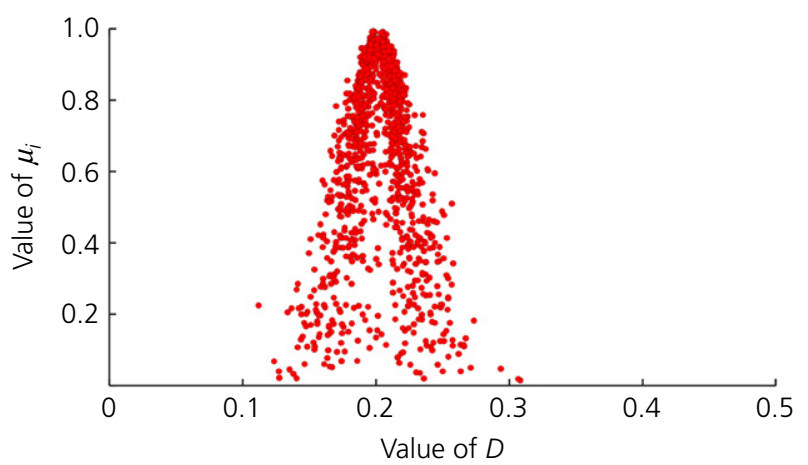

Figure 5. Initial consistency check of risk assessment for risk event (B1) evaluation is shown in Figure 6. It can be seen that the cloud diagram has a low degree of cloud droplet dispersion, which indicates that the expert judgement results are consistent.

In the same way, the risk value of each security risk event is finally obtained: $D^{\prime}=[0.197,0.048,0.052,0.065,0.076,0.035$, $0.044,0.028,0.037]$, and the corresponding risk levels are [high, moderate, moderate, moderate, moderate, low, moderate, low, low]. It can be seen that the failure accident of the bracket belongs to the high risk level, so it is necessary to carry out a special risk assessment and formulate risk reduction measures.

\section{Risk assessment prospects}

If the safety risk event is comprehensively considered using the traditional four aspects of personnel, materials, machinery and equipment, and the environment, there is a certain degree of difficulty in risk prediction. If only human factors and environmental factors are considered (Tian et al., 2015; Zhou et al., 2008), then the risk prediction can be realised with high accuracy.

\subsection{Assessment theory based on human and environmental factors}

The risk assessment theory of human factors is mainly based on the unqualified rate of human factors. Human factors are

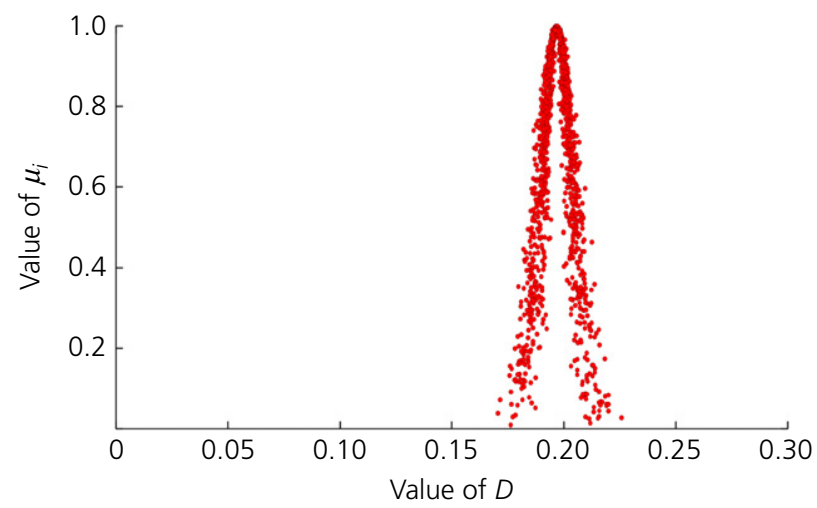

Figure 6. Second consistency check of risk assessment for risk event (B1) 
Table 8. Expression of each influencing factor

\begin{tabular}{|lccccccc}
$\begin{array}{l}\text { Human and environmental } \\
\text { factors }\end{array}$ & $\begin{array}{c}\text { Physical } \\
\text { A }\end{array}$ & $\begin{array}{c}\text { Psychological } \\
\text { B }\end{array}$ & $\begin{array}{c}\text { Quality } \\
\text { C }\end{array}$ & $\begin{array}{c}\text { Education } \\
\text { D }\end{array}$ & $\begin{array}{c}\text { Technology } \\
\text { E }\end{array}$ & $\begin{array}{c}\text { Environmental } \\
\text { H }\end{array}$ & $\begin{array}{c}\text { Risk level, } \\
\text { S }\end{array}$ \\
\hline Initial failure rate & K1 & K2 & K3 & K4 & K5 & K6 & S1 \\
Failure rate after taking & k1 & k2 & k3 & k4 & k5 & k6 & S2 \\
$\quad$ measures & & & & & & &
\end{tabular}

divided into five components: physical, psychological, quality, education and technology, which are expressed by A, B, C, $\mathrm{D}$ and $\mathrm{E}$, respectively. In addition, the influence of the environmental factor is expressed by $\mathrm{H}$, as shown in Table 8 .

The principle of calculating the failure rate is to conduct a survey by questionnaire (various forms of questionnaires) or skill assessments of human factors (physical, psychological, quality, educational and technical factors) for all construction personnel on the project, and then count the number of unqualified human factors. The failure rate can be calculated by the following formula:

$$
k=\frac{n}{m},(n \text { and } m \text { are integers, and } n \leq m)
$$

where $n$ is the number of unqualified persons; and $m$ is the total number of construction personnel.

The principle of the degree of impact of environmental factors is to invite a number of experts to conduct field inspections on the living environment, the working environment and the natural environment of the project, and score them according to the environmental impact degree table. Then the value of the environmental impact degree is comprehensively obtained. The specific risk prediction process is shown in Figure 7.

\subsection{Risk prediction based on Matlab-BP neural network theory}

Two sets of 30 groups of data (see Table 9) are taken randomly in this section, including the human factors failure rate, the impact rate of environmental factors on the project and the risk prediction level. Matlab software is adopted to train

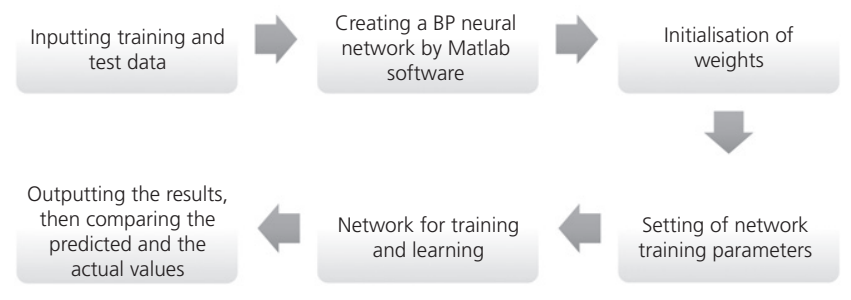

Figure 7. Flowchart of risk forecast the input sample data and obtain the internal rules of the data, which is used in the risk prediction. The first 25 groups of data in each set are used as BP-neural network training samples. The six types of influencing factors are input, the corresponding risk level is output, the maximum number of learning iterations is 20000 and the learning rate is 0.01 . So the remaining five groups of data are predicted samples and compared with actual values.

The graph predicted by the Matlab-BP neural network theory is shown in Figure 8. From Matlab-BP neural network analysis of two sets of 30 groups of data, it is found that the difference between the actual value and the predicted value is small, no matter whether the given test sample data group is regular, it can be predicted by the neural network.

Real-time risk prediction in time dimension - the risk prediction described above is for the project as a whole, and the amount of risk in the construction process of the actual project may change at any time. Therefore, a certain method can be set by the computer to determine the risk level of each day during the construction process, and the process is shown in Figure 9. The realisation of the real-time prediction process of project risk can greatly reduce the probability of occurrence of risk events, and at the same time, the trend of project risk quantity can be clearly known by recording the daily risk level of the project to assess the stability of project risk.

Real-time risk prediction in spatial dimension - the process of determining the level of risk in certain work areas is shown in Figure 10. The spatial prediction results of engineering risk can further reduce the probability of occurrence of risk accidents, and have a significant effect on reducing the accident rate in some high-risk areas.

Risk assessment based on human factors and environmental factors has the advantages of considerable accuracy, a concise process of risk assessment, the timeliness of risk assessment results and low investment in risk assessment. Because the traditional safety risk assessment method only assesses the overall risk, it does not consider the time and space risks of the actual project construction process; only the result risk is considered and the process risk is ignored. Therefore, under the same conditions, after the Matlab-BP neural network 
Table 9. The two sets of randomly extracted data

\begin{tabular}{|c|c|c|c|c|c|c|c|c|}
\hline & $\begin{array}{l}\text { Physical } \\
\text { factor }\end{array}$ & $\begin{array}{l}\text { Psychological } \\
\text { factor }\end{array}$ & $\begin{array}{l}\text { Quality } \\
\text { factor }\end{array}$ & $\begin{array}{l}\text { Education } \\
\text { factor }\end{array}$ & $\begin{array}{l}\text { Technology } \\
\text { factor }\end{array}$ & $\begin{array}{l}\text { Environmental } \\
\text { factor }\end{array}$ & $\begin{array}{l}\text { Risk level } \\
\text { (A) }\end{array}$ & $\begin{array}{l}\text { Risk level } \\
\text { (B) }\end{array}$ \\
\hline 1 & 0.030 & 0.151 & 0.211 & 0.458 & 0.291 & 0.368 & 2 & 4 \\
\hline 2 & 0.341 & 0.351 & 0.047 & 0.001 & 0.270 & 0.197 & 3 & 3 \\
\hline 3 & 0.021 & 0.333 & 0.299 & 0.231 & 0.435 & 0.342 & 2 & 4 \\
\hline 4 & 0.036 & 0.270 & 0.235 & 0.212 & 0.132 & 0.352 & 3 & 3 \\
\hline 5 & 0.261 & 0.349 & 0.348 & 0.230 & 0.159 & 0.221 & 3 & 4 \\
\hline 6 & 0.048 & 0.333 & 0.350 & 0.385 & 0.060 & 0.010 & 3 & 3 \\
\hline 7 & 0.409 & 0.089 & 0.319 & 0.161 & 0.470 & 0.165 & 4 & 4 \\
\hline 8 & 0.409 & 0.064 & 0.017 & 0.392 & 0.323 & 0.212 & 3 & 4 \\
\hline 9 & 0.361 & 0.500 & 0.034 & 0.236 & 0.240 & 0.135 & 3 & 4 \\
\hline 10 & 0.075 & 0.086 & 0.160 & 0.018 & 0.320 & 0.099 & 2 & 2 \\
\hline 11 & 0.330 & 0.016 & 0.265 & 0.088 & 0.272 & 0.411 & 3 & 4 \\
\hline 12 & 0.259 & 0.281 & 0.327 & 0.361 & 0.324 & 0.215 & 3 & 4 \\
\hline 13 & 0.486 & 0.441 & 0.204 & 0.237 & 0.272 & 0.444 & 2 & 5 \\
\hline 14 & 0.324 & 0.335 & 0.410 & 0.076 & 0.361 & 0.196 & 3 & 4 \\
\hline 15 & 0.400 & 0.095 & 0.359 & 0.171 & 0.261 & 0.385 & 4 & 4 \\
\hline 16 & 0.227 & 0.184 & 0.484 & 0.304 & 0.497 & 0.198 & 3 & 5 \\
\hline 17 & 0.216 & 0.230 & 0.266 & 0.096 & 0.109 & 0.404 & 3 & 3 \\
\hline 18 & 0.413 & 0.491 & 0.163 & 0.369 & 0.053 & 0.378 & 2 & 5 \\
\hline 19 & 0.042 & 0.078 & 0.053 & 0.121 & 0.055 & 0.189 & 2 & 1 \\
\hline 20 & 0.067 & 0.428 & 0.305 & 0.459 & 0.032 & 0.108 & 3 & 4 \\
\hline 21 & 0.087 & 0.322 & 0.389 & 0.135 & 0.202 & 0.395 & 3 & 4 \\
\hline 22 & 0.195 & 0.188 & 0.212 & 0.383 & 0.224 & 0.475 & 3 & 4 \\
\hline 23 & 0.416 & 0.095 & 0.045 & 0.094 & 0.183 & 0.164 & 3 & 3 \\
\hline 24 & 0.402 & 0.214 & 0.133 & 0.144 & 0.382 & 0.336 & 4 & 4 \\
\hline 25 & 0.030 & 0.241 & 0.077 & 0.046 & 0.314 & 0.219 & 4 & 3 \\
\hline 26 & 0.200 & 0.060 & 0.141 & 0.288 & 0.386 & 0.417 & 2 & 4 \\
\hline 27 & 0.263 & 0.295 & 0.220 & 0.342 & 0.466 & 0.384 & 2 & 5 \\
\hline 28 & 0.208 & 0.113 & 0.264 & 0.273 & 0.486 & 0.084 & 3 & 4 \\
\hline 29 & 0.328 & 0.192 & 0.229 & 0.213 & 0.096 & 0.431 & 4 & 4 \\
\hline 30 & 0.314 & 0.291 & 0.438 & 0.322 & 0.069 & 0.495 & 2 & 5 \\
\hline
\end{tabular}

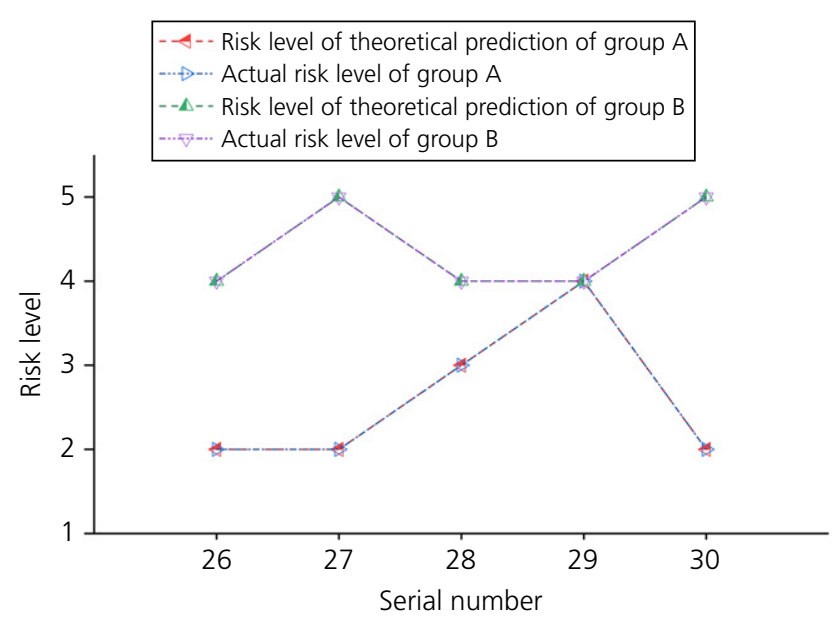

Figure 8. Comparison of actual and predicted values of sample data in groups $A$ and $B$

theory has predicted the real-time and spatial risks in the construction process, corresponding measures can be taken in time which can reduce the probability of risk occurrence.
Test all workers at the construction site and store the results in the computer

Implement the punch card system of the staff and record their work status for the day

Use the BP-neural network theory based on the recorded information to obtain the predicted amount of risk for the day

Take appropriate precautions based on predicted results

Figure 9. Real-time risk prediction process based on time dimension 


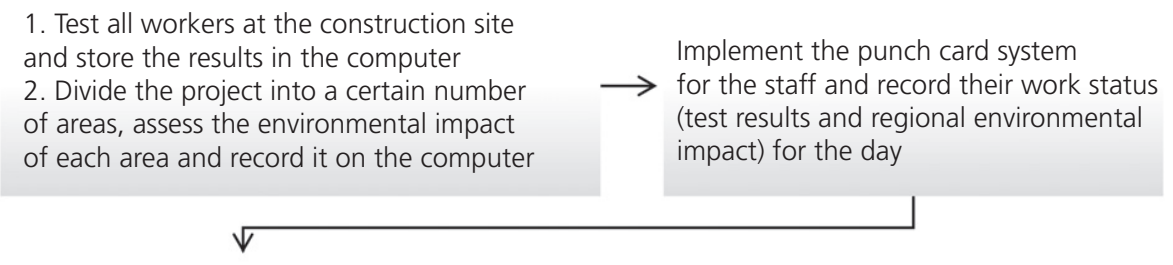

Use the BP-neural network theory based on the recorded information $\longrightarrow$ Take appropriate precautions to obtain risk predictions for different based on predicted results regions of the day

Figure 10. Real-time risk prediction process based on spatial dimension

Of course, there is almost no test behaviour of human factors and environmental factors in an actual engineering project, and the actual failure rate of human and environmental factors is very difficult to obtain from previous engineering cases; this is the biggest difficulty when using Matlab-BP neural network theory to predict the risks. At the same time, to collect test results on human and environmental factors for all kinds of projects in a short time involves the necessary investment of more manpower, material and financial resources, so this paper simply puts forward the risk prediction system as a new research method.

\section{Conclusions}

(a) After collecting the case list of risk events for previous bridge construction, nine kinds of risk events were obtained, among which the failure of the bracket, high-altitude fall, destruction of mouldboard and mechanical injury had the highest occurrence of risk during the construction process of the bridge.

(b) Using the AHP, a cloud theory model and an improved LEC method to analyse the types of safety accidents that may occur in the cast-in-situ construction of a high-pier interchange box girder in a mountainous area, it is concluded that the risk level of bracket failure can be categorised as high risk.

(c) The impact of human and environmental factors on risk prediction is considered and the Matlab-BP neural network method is proposed to predict the risk. At the same time, in order to reduce the probability of occurrence of risk events, real-time risk prediction in time and space dimensions are necessary.

(d) Because of the addition of 'intelligence', the risk assessment of future bridge projects has more possibilities, as follows. (i) Based on digital measurement technology and building information modelling technology to establish an engineering risk source monitoring terminal, which can carry out real-time dynamic monitoring of various risk sources during construction, a Bayes dynamic risk assessment model is established, combining the risk source mega data collected by the real-time monitoring terminal with artificial intelligence analysis technology, so the risk events can be dynamically assessed during the construction process to improve the intelligent level of engineering safety management. (ii) A standard database of engineering safety risks is established to realise the transmission and sharing of information for various engineering projects, to enable quick general judgements to be made for the risk assessment of a specific engineering case.

\section{Acknowledgements}

This paper is partially supported by the National Natural Science Foundation of China (51478071), the Entrepreneurship and Innovation Support Plan of Overseas Returnees of Chongqing (cx2018113) and the State Key Laboratory of Mountain Bridge and Tunnel Engineering (CQSLBF-Y14-3), as well as the Scientific Projects of Mountain Bridges and Material Engineering Research Center of the Ministry of Education (QLZX-2012-3, QLZX-2012-5).

\section{REFERENCES}

Chen XW (2016) Psychological assessment data processing model based on neural network theory. In Proceedings of the 2016 International Conference on Economics and Management Innovations (ICEMI 2016). Atlantis Press, Hong Kong, China, pp. 182-185.

Deng X, Li JM, Zeng HJ, Chen JY and Zhao JF (2012) Analysis and application of AHP weight calculation method. Mathematics in Practice and Theory 42(7): 93-100.

Fan ZY (2011) BP Neural network model and learning algorithm. Software Guide 10(7): 66-68. 
He C, Li M, Li TT et al. (2016) Comparison and analysis of the four methods of determining weights in multi-objective comprehensive evaluation. Journal of Hubei University (Natural Science) 38(2): 172-178.

Ji N and Cai HX (2016) The quality prediction of fiber-optic gyroscope based on the grey theory and BP neural network. In Proceedings of the 6th International Workshop of Advanced Manufacturing and Automation (IWAMA 2016). Atlantis Press, Paris, France, pp. $130-137$.

Li DY and Meng HJ (1995) Membership and membership cloud generator. Computer Research and Development 32(6): 15-20.

Li DY, Liu CY and Gan WY (2009) A new cognitive model: cloud model. International Journal of Intelligent Systems 24(3): 357-375.

Liu H and Sun SM (2015) Study on the construction safety assessment of highway tunnels based on the improved LEC method. Modern Tunneling Technology 52(1): 26-32+61.

Liu XJ and Zhang K (2018) Optimal schemes of bridge construction based on weighted rank sum ration method. Journal of Chongqing Jiaotong University (Natural Science Edition) 37(10): 21-25.

Liu YL, Huang XL, Duan J and Zhang HM (2017) The assessment of traffic accident risk based on grey relational analysis and fuzzy comprehensive evaluation method. Natural Hazards 88(3): $1409-1422$.

Lu SJ, Xiao XH and Chen HX (2014) Construction technology of high pier bridge on highway. Highway Technology of Transportation (Application Technology Edition) 10(5): 198-199.

Nariman NA (2017) Aerodynamic stability parameters optimization and global sensitivity analysis for a cable stayed bridge. KSCE Journal of Civil Engineering 21(5): 1866-1881.
Raka C and Liangrokapart J (2017) An analytical hierarchy process (AHP) approach to risk analysis: a case study of a new generic drug development process. Journal of Pharmaceutical Innovation 12(4): 319-326.

Tang CG, Luo ZL, Zhou KY and Yang KL (2015) Application of improved LEC method in safety evaluation of highway bridge construction. Northern Communications 12: 25-27+30.

Tian B, Hu JQ, Wang HT and Li KW (2015) Study on the control method of human error for fracturing operation based on check land methodology. In Proceedings of the 2015 International Field Exploration and Development Conference (2015IFEDC). Shaanxi Petroleum Society, Xian, China, pp. 655-662.

Tong RP and Yang XY (2017) Environmental health risk assessment of contaminated soil based on Monte Carlo method: a case of PAHs. Environmental Science 38(6): 2522-2529.

Yazdi M, Nikfar F and Nasrabadi M (2017) Failure probability analysis by employing fuzzy fault tree analysis. International Journal of System Assurance Engineering and Management 8(2): 1177-1193.

Yin SQ, Liang FY and Yao XQ (2011) Dynamic risk prediction for the deep excavations based on neutral networks and its applications. Chinese Journal of Underground Space and Engineering 7(5): 996-1000 + 1012.

Zayed T, Amer M and Pan JY (2007) Assessing risk and uncertainty inherent in Chinese highway projects using AHP. International Journal of Project Management 26(4): 408-419.

Zhou G, Cheng WM, ZhuGe FM and Nie W (2008) Analysis and exploration on correlative theories of man-made errors and human unsafe behaviors. Chinese Safety Science Journal 3: $10-14+176$.

\section{How can you contribute?}

To discuss this paper, please email up to 500 words to the editor at journals@ice.org.uk. Your contribution will be forwarded to the author(s) for a reply and, if considered appropriate by the editorial board, it will be published as discussion in a future issue of the journal.

Proceedings journals rely entirely on contributions from the civil engineering profession (and allied disciplines). Information about how to submit your paper online is available at www.icevirtuallibrary.com/page/authors, where you will also find detailed author guidelines. 